\title{
UMA ANÁLISE DO PACTO DE NÃO CONCORRÊNCIA APÓS O TÉRMINO DA RELAÇÃO DE EMPREGO SOB UMA ÓTICA CONSTITUCIONAL
}

\author{
AN ANALYSIS OF THE NON COMPETITION AGREEMENT AFTER THE \\ TERMINATION OF THE EMPLOYMENT RELATIONSHIP UNDER A \\ CONSTITUTIONAL PERSPECTIVE
}

\author{
${ }^{1}$ Raphaela Magnino Rosa Portilho \\ ${ }^{2}$ Ricardo José Leite de Sousa
}

\section{RESUMO}

O presente artigo busca analisar a celebração do pacto de não concorrência após o término da relação de emprego no âmbito do ordenamento jurídico brasileiro. O estudo implica a necessidade de verificação dos limites que podem ser impostos ao direito de liberdade de trabalho, que é garantido no art. 5º inciso XIII, da Constituição de 1988, objetivando demonstrar que a pactuação da não concorrência não atenta contra essa garantia constitucional. Para tanto, a investigação também abarcará o conflito entre a liberdade de trabalho e a livre iniciativa e concorrência, todos direitos constitucionalmente garantidos, analisando a possibilidade de estabelecer-se uma composição que observe a proporcionalidade dos direitos cuja proteção é almejada.

Palavras-chave: Pacto de não concorrência, Liberdade de trabalho, Livre iniciativa, Livre concorrência

\begin{abstract}
This article seeks to analyze the non-competition agreement after the termination of the employment relationship under the Brazilian legal system. The study implies the need to verify the limits that can be imposed on the right to freedom of work, which is guaranteed in art. 5, item XIII of the 1988 Constitution, aiming to show that the pact of non-competition does not violate this constitutional guarantee. Therefore, the research will also cover the conflict between freedom of labor and free enterprise and competition, all constitutionally guaranteed rights, analyzing the possibility of setting up a composition able to observe the proportionality of rights whose protection is desired.
\end{abstract}

Keywords: Non- competition agreement, Freedom of labor, Free enterprise, Free competition

\footnotetext{
${ }^{1}$ Mestre em Direito pela Universidade do Estado do Rio de Janeiro - UERJ, Rio de Janeiro (Brasil). Professora da Universidade Federal Rural do Rio de Janeiro - UFRRJ, Rio de Janeiro (Brasil). E-mail: raphaelamrp@ hotmail.com ${ }^{2}$ Mestre em Direito pela Universidade do Estado do Rio de Janeiro - UERJ, Rio de Janeiro (Brasil). E-mail: ricardo.sousa@loureiromaia.com.br
} 


\section{INTRODUÇÃ̃}

A preocupação com a concorrência desleal permeia diversos campos do Direito no ordenamento brasileiro, sendo verificada desde a tipificação do crime de concorrência desleal, previsto no artigo 195 da Lei $\mathrm{n}^{\circ}$ 9.279/1996; passando pelas restrições impostas ao sócio retirante, que é obrigado a não atuar em sociedade empresária concorrente ou é submetido a uma limitação espacial para o exercício de sua atividade empresarial, de acordo com a dicção do artigo 1.147 do Código Civil de 2002 e chegando ao Direito do Trabalho, em que há previsão para rescisão contratual por justa causa do empregado, quando se verifica prática de ato de concorrência ao seu empregador, de acordo com o artigo 482, alínea "c", da Consolidação das Leis do Trabalho (CLT), ou de ato que viole segredo da empresa, consoante o artigo 482, alínea “g”, da CLT.

Relativamente à preservação de informações sigilosas e de segredo de negócio mediante a celebração de pacto de não concorrência após a rescisão do contrato de trabalho, matéria sobre a qual se estrutura o presente estudo, observa-se que a globalização da economia impõe um modelo de tamanha competitividade, que faz com que a relação de emprego assuma um elevado grau de complexidade, especialmente no que se refere aos empregados que têm acesso a informações importantes para a manutenção e disputa dos mercados em que seus empregadores estão inseridos.

Objetivando manter ou atrair clientela, bem como conquistar novos mercados, procurase não só a proteção das técnicas utilizadas na produção, mas também evitar que ex-empregados que tiveram acesso a informações que possuam valor concorrencial venham a propagar o conhecimento adquirido, trazendo prejuízo ao antigo empregador.

O estudo ora apresentado tem por objetivo, de modo geral, analisar a relação existente entre a concorrência e o contrato de trabalho, discutindo a validade ou não da cláusula contratual de não concorrência após a extinção da relação de emprego sob a ótica do ordenamento constitucional vigente buscando responder a seguinte indagação: a celebração do pacto de não concorrência atenta contra o direito fundamental de liberdade de trabalho?

Para alcançar a resposta, serão revisitadas todas as Cartas Constitucionais que o Brasil teve, de maneira a consultar as garantias que foram conferidas para a liberdade de trabalho, confrontando-as com os direitos que cada Constituição assegurou em favor da livre concorrência, da livre iniciativa e da proteção à propriedade privada. 
Com esse estudo, tem-se o propósito de entender se a liberdade de trabalho encontra restrições e limites em outros direitos constitucionais, mormente os acima indicados.

Em se concluindo que é possível a imposição de limites à liberdade de trabalho, o estudo tentará responder se a celebração do pacto de não concorrência é um instrumento razoável e próprio para exercício de tal limitação.

É importante registrar a relevância do estudo ora proposto, uma vez que este busca solucionar uma controvérsia que se apresenta de forma reiterada em disputas judiciais. Cumpre observar, finalmente, que a presente investigação se consubstancia em uma pesquisa qualitativa do tipo teórico, destacado seu caráter conceitual, de cunho propositivo, pautada no método de análise de conteúdo através da utilização da documentação indireta enquanto técnica de pesquisa.

\section{O CONFRONTO ENTRE A LIBERDADE DE TRABALHO E A LIVRE INICIATIVA E CONCORRÊNCIA NOS TEXTOS CONSTITUCIONAIS BRASILEIROS}

Ponto nodal para a compreensão da controvérsia e verificação da possibilidade de celebração do pacto de não concorrência após o término da relação de emprego reside na análise e ponderação de garantias constitucionais vigentes que, aparentemente, se encontram em rota de colisão.

De um lado, existe a garantia à liberdade de trabalho. Do outro, à livre iniciativa e à livre concorrência ${ }^{1}$.

Assim, antes de passar à análise do conflito existente entre as garantias constitucionais em tela, na hipótese de celebração do pacto de não concorrência, objetivando alcançar uma solução harmônica, é importante definir o que seja a liberdade de trabalho, bem como a liberdade de iniciativa, salientando-se a necessidade de inserir a concorrência no contexto constitucional.

De acordo com Cesarino Júnior (1970, p.10), “a liberdade de trabalho é a forma de liberdade individual que consiste na faculdade de escolher e exercer a profissão nas condições que convenham ao interessado".

José Afonso da Silva (1997, p.249), ao comentar o art. 5º, inciso XIII, da Carta Constitucional de $1988^{2}$, afirma que o dispositivo confere uma liberdade individual, que não

\footnotetext{
${ }^{1}$ Cf. Art. 5º XIII e Art. 170 da Constituição Federal de 1988.
} 
se confunde com garantia de cunho social, uma vez que o texto em análise garante apenas a liberdade de escolha de ofício e de profissão, de acordo com as pretensões de cada pessoa e na medida de seus próprios esforços e sorte.

Para o autor, a própria Constituição impõe limites a esse direito, ao ressalvar que o exercício de determinadas profissões depende da observância das qualificações profissionais que a lei exigir (SILVA, 1997, p.250).

Prossegue o jurista explicando que a garantia do direito social ao trabalho não está expressa em nenhum dos artigos da Constituição Federal de 1988, mas pode ser verificada na conjugação de diversas previsões constitucionais:

\begin{abstract}
$\mathrm{O}$ art. $6^{\circ}$ define o trabalho como direito social, mas nem ele nem o art. $7^{\circ}$ trazem norma expressa conferindo o direito ao trabalho. Este, porém, ressai do conjunto de normas da Constituição sobre o trabalho. Assim, no art. $1^{\circ}$, IV, se declara que a República Federativa do Brasil tem como fundamento, entre outros, os valores sociais do trabalho; o art. 170 estatui que a ordem econômica funda-se na valorização do trabalho, e o art. 193 dispõe que a ordem social tem como base o primado do trabalho. Tudo isso tem o sentido de reconhecer o direito social ao trabalho, como condição da efetividade da existência digna (fim da ordem econômica) e, pois, da dignidade da pessoa humana, fundamento, também, da República Federativa do Brasil (art. $1^{\circ}$, III). E aqui se entroncam o direito individual ao livre exercício de qualquer trabalho, ofício ou profissão, com o direito social ao trabalho, que envolve o direito de acesso a uma profissão, à orientação e formação profissionais, à livre escolha do trabalho, assim como o direito à relação de emprego (art. $\left.7^{\circ}, \mathrm{I}\right)$ e o seguro-desemprego, que visam, todos, entre outros, à melhoria das condições sociais dos trabalhadores. (SILVA, 1997, p.280-281)
\end{abstract}

Em relação à livre iniciativa, José Afonso da Silva (1997, p. 724) afirma que ela "envolve a liberdade de indústria e comércio ou liberdade de empresa e a liberdade de contrato [...] como um dos esteios da ordem econômica [...] que assegura a todos o livre exercício de qualquer atividade econômica".

Prossegue o autor esclarecendo que a livre concorrência é um dos princípios da ordem econômica nacional, sendo uma manifestação da liberdade de iniciativa (SILVA, 1997, p.726).

É interessante observar que a garantia da liberdade de trabalho e da livre iniciativa e concorrência não são novidades do texto constitucional vigente, eis que estiveram presentes, de uma forma ou de outra, ao longo das Cartas Constitucionais que o antecederam.

\footnotetext{
2 “Art. $5^{\circ}$ Todos são iguais perante a lei, sem distinção de qualquer natureza, garantindo-se aos brasileiros e aos estrangeiros residentes no País a inviolabilidade do direito à vida, à liberdade, à igualdade, à segurança e à propriedade, nos termos seguintes: $[\ldots]$ XIII - é livre o exercício de qualquer trabalho, ofício ou profissão, atendidas as qualificações profissionais que a lei estabelecer;” BRASIL. Constituição da República Federativa do Brasil de 1988. Diário Oficial da União. Disponível em: < http://www.planalto.gov.br/ccivil_03/constituicao/constituicao.htm>. Acesso em: 20 jan 2014.
} 
A Constituição de 1824, de inspiração claramente liberal, proclamava a liberdade de trabalho, indústria e comércio, abolindo as corporações de ofício, nos mesmos moldes em que ocorrera na França após a Revolução ${ }^{3}$.

De acordo com Evaristo de Moraes Filho (1986, p. 135), “o trabalho livre continuava regulado pelas disposições 29 a 35, do livro IV das Ordenações do Reino”, tendo o texto constitucional limitado-se a garantir o exercício de escolha da profissão a ser exercida.

A Constituição de 1891 trouxe poucos avanços em relação ao texto constitucional anterior.

Marcadamente liberal, manteve a previsão de que era "livre o exercício de qualquer profissão moral, intelectual ou industrial" ${ }^{\text {, }}$, sem, contudo, fazer as ressalvas existentes na Constituição de 1824, relativamente aos costumes públicos, à segurança e à saúde dos cidadãos.

De acordo com Segadas Vianna (1957, p. 56), trata-se de uma Carta Constitucional oriunda de uma assembleia dominada por ideias liberais e individualistas, cujo produto não demonstrou nenhuma preocupação quanto à proteção ao trabalho e ao trabalhador, firmando- se na concepção da total soberania da vontade individual, deixando a cargo dos próprios trabalhadores a defesa de seus interesses.

Em seguida, a Constituição de 1934 veio romper com o paradigma liberal até então predominante, abraçando um modelo social-democrata. Com forte inspiração na Constituição de Weimar, de 1919, instituiu um título dedicado exclusivamente à "ordem econômica e social" (MORAES FILHO, 1986, p. 162).

Pedro Calmon esclarece que a Constituição de 1934

\begin{abstract}
Ampliou, extraordinariamente, o Govêrno Federal, a sua ação, no campo das atividades econômicas. A Constituição de 1934 não é mais liberal democrática, porém social democrática. Institui Justiça do Trabalho, salário mínimo, limitação de lucros, nacionalização de empresas, direta intervenção do Estado para normalizar, utilizar ou orientar as fôrças produtoras, organização sindical. Ao direito de propriedade impôs um limite: o interesse social ou coletivo, na forma que a lei determinar. $(1937$, p.15)
\end{abstract}

\footnotetext{
3 “Art. 179. A inviolabilidade dos Direitos Civis, e Politicos dos Cidadãos Brazileiros, que tem por base a liberdade, a segurança individual, e a propriedade, é garantida pela Constituição do Imperio, pela maneira seguinte. [...]

XXIV. Nenhum genero de trabalho, de cultura, industria, ou commercio póde ser prohibido, uma vez que não se opponha aos costumes publicos, á segurança, e saude dos Cidadãos.

XXV. Ficam abolidas as Corporações de Officios, seus Juizes, Escrivães, e Mestres.

XXVI. Os inventores terão a propriedade das suas descobertas, ou das suas producções. A Lei lhes assegurará um privilegio exclusivo temporario, ou lhes remunerará em ressarcimento da perda, que hajam de soffrer pela vulgarisação.” BRASIL. Constituição Política do Império do Brazil (de 25 de março de 1824). Disponível em: <http://www.planalto.gov.br/ccivil_03/Constituicao/Constitui\%C3\%A7ao24.htm>. Acesso em: 24 mar 2013.

${ }^{4}$ Art. 72, §24, da Constituição de 1891. BRASIL. Constituição da República dos Estados Unidos do Brasil (de 24 de fevereiro de 1891). Disponível em: < http://www.planalto.gov.br/ccivil_03/constituicao/constituicao91.htm>. Acesso em: 5 jul 2015.
} 
Verifica-se que o texto constitucional estabeleceu firmes limites à liberdade econômica e ao direito de propriedade, fixando o interesse social ou coletivo como norte a ser buscado. Quanto à liberdade de trabalho, a Carta Constitucional em comento traz importantes modificações em relação às Constituições anteriores. Os direitos individuais são previstos no artigo 113, sendo que a liberdade de trabalho é assegurada em seu item 13, que afirma ser "livre o exercício de qualquer profissão, observadas as condições de capacidade técnica e outras que a lei estabelecer, ditadas pelo interesse público"5.

O exercício da profissão passa a ter limites que anteriormente não eram impostos. Primeiramente, observa-se que determinadas profissões dependem de capacitação técnica específica, não podendo ser desempenhadas por pessoas não habilitadas. Em segundo lugar, a liberdade de trabalho passou a ser tolhida pelo interesse público.

Pouco mais de três anos haviam se passado quando o golpe de Estado de 10 de outubro de 1937 outorgou ao país uma nova Constituição, de cunho corporativista, inspirada em seu aspecto político pela constituição polonesa e em sua orientação econômico-social pela Carta del Lavoro italiana (MORAES FILHO, 1986, p. 162).

A despeito disso, Segadas Vianna (1957, p.62) defende que seu conteúdo, quanto às relações de trabalho, era mais protetivo do que aqueles existentes na Constituição que a antecedeu, destacando que, de acordo com seu artigo 136, o trabalho é um dever social, tendo direito à proteção e solicitude especiais do Estado.

Apesar de o texto constitucional em comento garantir a liberdade de trabalho em seu artigo 122 , item $8^{\circ}$, temperando-a com as "as condições de capacidade e as restrições impostas pelo bem público", trabalho, de uma liberdade individual, em direito social, ao determinar que

a todos é garantido o direito de subsistir mediante o seu trabalho honesto e este,
como meio de subsistência do indivíduo, constitui um bem que é dever do Estado
proteger, assegurando-lhe condições favoráveis e meios de defesa.

Não se trata mais de assegurar a cada cidadão o direito de escolher a profissão que deseja seguir, relegando ao seu próprio esforço a obtenção do trabalho, mas sim de assegurar que todos tenham o direito de trabalhar.

\footnotetext{
BRASIL. Constituição da República dos Estados Unidos do Brasil (de 16 de julho de 1934). Disponível em: <http://www.planalto.gov.br/ccivil_03/constituicao/constituicao34.htm>. Acesso em: 5 jul 2015.

${ }^{6}$ Art. 122, item $8^{\circ}$, da Constituição de 1937. BRASIL. Constituição da República dos Estados Unidos do Brasil (de 10 de novembro de 1937). Disponível em: < http://www.planalto.gov.br/ccivil_03/constituicao/constituicao37.htm>. Acesso em: 5 jul 2015.

${ }_{7}^{7}$ Artigo 136 da Constituição de 1937. Idem
} 
Ainda de acordo com Segadas Vianna (1957, p. 62), a Constituição de 1937, no âmbito das relações de trabalho, apresentou avanços ao estipular preceitos básicos para repouso semanal remunerado, indenização pela rescisão do contrato de trabalho por iniciativa do empregador sem justo motivo, férias remuneradas, salário mínimo, fixação da jornada de oito horas diárias, proteção ao trabalho da mulher e do menor e seguro social.

O texto constitucional de 1937, seguindo sua linha corporativista, negou expressamente o direito de greve, que foi declarado um recurso antissocial, nocivo aos interesses do trabalho e do capital ${ }^{8}$.

No âmbito da ordem econômica, o intervencionismo do Estado se fez sentir de forma contundente.

A livre iniciativa já não era tão livre. A garantia do dirigismo vem estampada no artigo 135, o qual determinava que a iniciativa privada deveria ser exercida nos limites do poder público, que poderia intervir no domínio econômico, objetivando suprir deficiências da iniciativa individual ou coordenar os fatores da produção, de acordo com os interesses da nação, podendo a intervenção se dar sob a forma de controle, estímulo ou gestão direta.

Encerrado o período de ditadura, sobreveio a Constituição de 1946, classificada por Evaristo de Moraes Filho (1986, p. 165) como inovadora e atual, tendo-se aproveitado das conquistas do pós-guerra no campo da racionalização do Direito e do Estado de bem-estar.

A opinião de Segadas Vianna é ainda mais lisonjeira ao texto constitucional de 1946. Como um dos integrantes daquela Assembleia Constituinte, o autor afirma ter defendido que aquela Carta Magna deveria registrar os princípios básicos do Direito do Trabalho, afirmando um conteúdo social do qual resultaria a segurança das instituições (SÜSSEKIND, MARANHÃO, VIANNA 1957, p. 62).

Por isso, a seu ver, a Constituição de 1946 "encerra um conteúdo social que a coloca entre as mais completas do mundo" (SÜSSEKIND; MARANHÃO; VIANNA 1957, p. 62).

De fato, o texto constitucional avançou em diversos aspectos, garantindo pela primeira vez o direito de greve (artigo 158), a participação obrigatória dos trabalhadores nos lucros das empresas (artigo 157, IV) e a proibição de trabalho noturno ao menor (artigo 157, IX).

A liberdade do exercício de profissão foi restabelecida, sem a restrição decorrente do interesse público que existia na Constituição anterior, ficando, limitada, apenas, pela capacitação técnica do indivíduo 9 . 
E, ao tratar da ordem econômica e social, a Constituição de 1946 declara pela primeira vez, em seu artigo 146, que as atividades econômicas devem ser organizadas de acordo com os princípios da justiça social, conciliando a liberdade de iniciativa com a valorização do trabalho humano.

O parágrafo único desse mesmo artigo afirma que o trabalho é uma obrigação social, que deve assegurar a todos uma existência digna. Nesse aspecto, a previsão constitucional de que cabe ao Estado garantir o acesso ao trabalho demonstra uma herança do texto de 1937.

No que se refere à intervenção do Estado no domínio econômico, o artigo 145 da Constituição de 1946 reproduziu, com pequenas alterações, a redação do artigo 116 da Carta de 1934, aduzindo que, observados o interesse público e os direitos fundamentais garantidos no texto constitucional, é possível à União intervir no domínio econômico e monopolizar determinada indústria ou atividade.

A Constituição de 1934 ressalvava dessa possibilidade os serviços municipalizados e aqueles de competência dos poderes locais.

A Carta de 1946 foi a primeira a proclamar a repressão ao abuso do poder econômico objetivando a eliminação da concorrência (artigo 148), demonstrando o animus de se opor à concorrência desleal e às práticas de domínio de mercado.

Nova ruptura institucional sobreveio com o golpe civil-militar de 1964. A despeito disso, só foi lançado um novo texto constitucional no ano de 1967, que sofreu significativas modificações com a emenda de 1969.

Dentro do objeto do presente estudo, cumpre registrar que o artigo 160 da Carta outorgada em 1967, já com a redação dada pela emenda de 1969, dispunha que a ordem econômica tem por fim realizar a justiça social, devendo ser observados: i) a livre iniciativa; ii) a valorização do trabalho como condição da dignidade humana; iii) a função social da propriedade; iv) a harmonia e solidariedade entre as categorias sociais de produção; v) a repressão ao abuso do poder econômico, caracterizado pelo domínio dos mercados, a eliminação da concorrência e ao aumento arbitrário dos lucros; e vi) a expansão das oportunidades de emprego produtivo ${ }^{10}$.

\footnotetext{
9 "Art 141 - A Constituição assegura aos brasileiros e aos estrangeiros residentes no País a inviolabilidade dos direitos concernentes à vida, à liberdade, a segurança individual e à propriedade, nos termos seguintes:

$[\ldots]$

$\S 14$ - É livre o exercício de qualquer profissão, observadas as condições de capacidade que a lei estabelecer.” BRASIL. Constituição da República dos Estados Unidos do Brasil (de 18 de setembro de 1946). Disponível em: < http://www.planalto.gov.br/ccivil_03/constituicao/constituicao46.htm>. Acesso em: 5 jul 2015.

${ }_{10}$ Art. 160 da Emenda Constitucional no 1 de 1969. BRASIL. Emenda Constitucional no 1 (de 17 de outubro de 1969). Disponível em: < h http://www.planalto.gov.br/ccivil_03/constituicao/Emendas/Emc_anterior1988/emc01-69.htm>. Acesso em: 5 jul 2015.
} 
No que se refere à liberdade de trabalho, o texto do artigo $153, \S 23$, preconizava que o exercício de qualquer trabalho, ofício ou profissão é livre, desde que observadas as condições de capacidade que a lei estabelecer, com redação praticamente idêntica àquela dada pela Constituição de $1946^{11}$.

Vê-se que, já no texto Constitucional de 1969, a livre iniciativa estava limitada pela necessidade de valorizar o trabalho como condição da dignidade humana, sendo almejada a busca pela expansão das oportunidades de emprego, o que, à luz do estudo proposto, significa um conflito de normas a ser dirimido.

Esse conflito se aprofunda com a Constituição de 1988. Nela, a liberdade de trabalho vem estatuída no artigo $5^{\circ}$, inciso XIII, o qual assegura que o exercício de qualquer trabalho, ofício ou profissão é livre, sendo necessário, contudo, o atendimento das qualificações profissionais que a lei estabelecer ${ }^{12}$.

Em essência, não houve alteração substancial em relação ao texto constitucional anterior.

No entanto, as regras sobre a ordem econômica passaram a ter um cunho mais social, por força da previsão contida no artigo 170, amparada na valorização do trabalho humano e na livre iniciativa, objetivando assegurar a todos existência digna, conforme os ditames da justiça social (SILVA, 1997, p. 726-727) ${ }^{13}$.

Para tanto, a Carta de 1988 determinou que a ordem econômica deveria observar os seguintes princípios: i) soberania nacional; ii) propriedade privada, sendo ressalvada sua função social; iii) livre concorrência; iv) defesa do consumidor; v) defesa do meio ambiente; vi) redução das desigualdades regionais e sociais; vii) busca do pleno emprego; viii) tratamento favorecido para as empresas de pequeno porte constituídas sob as leis brasileiras e que tenham sua sede e administração no País.; ix) o livre exercício de qualquer atividade econômica, independentemente de autorização de órgãos públicos, salvo nos casos previstos em lei. ${ }^{14}$

Para o tema em estudo, importa destacar que o texto constitucional preservou a propriedade privada, respeitada sua função social, e a livre concorrência como princípios que devem nortear a ordem econômica.

José Afonso da Silva (1997, p. 726-727) explica que a livre concorrência é uma manifestação da liberdade de iniciativa, e, de forma a garanti-la, a Carta Constitucional de

\footnotetext{
${ }_{11}^{11}$ Art. 153, §23, da Emenda Constitucional no 1 de 1969. Idem.

${ }^{12}$ Art. $5^{\circ}$, XIII, Constituição de 1988. BRASIL. Constituição da república Federativa do Brasil (de 5 de outubro de 1988).

Disponível em: < http://www.planalto.gov.br/ccivil_03/constituicao/constituicaocompilado.htm>. Acesso em: 5 jul 2015.

13 Art. 170, caput, Constituição de 1988. Idem.

${ }^{14}$ Art. 170, incisos I a X e parágrafo único, Constituição de 1988. Idem.
} 
1988 assegura que a lei reprimirá o abuso do poder econômico que vise à dominação dos mercados, à eliminação da concorrência e ao aumento arbitrário dos lucros, conforme o disposto em seu artigo $173, \S 4^{\circ}$. Assim, a conjugação do texto dos artigos 170 e 173 da Constituição tem um mesmo objetivo: tutelar o sistema de mercado, protegendo a livre concorrência contra a tendência da concentração capitalista.

De outro vértice, a valorização do trabalho humano e a livre iniciativa deixaram de ser incisos do artigo e passaram a integrar seu caput, denotando a maior importância conferida pelo constituinte.

A Constituição avançou no tema "emprego", ao anotar que a ordem econômica deve buscar o pleno emprego e não somente a expansão de oportunidades de emprego produtivo.

Relativamente ao pleno emprego, José Afonso da Silva (1997, p. 728) afirma tratarse de um princípio diretivo da política econômica em oposição às políticas recessivas, que se coaduna com a regra de que a ordem econômica é fundada na valorização do trabalho humano.

Feita essa pequena análise sobre a evolução dos textos constitucionais quanto ao tema em apreço, constata-se que, quando se discute a possibilidade de celebração do pacto de não concorrência, deparamo-nos com uma colisão de direitos constitucionalmente garantidos. De um lado, o direito fundamental à liberdade de trabalho; de outro, a liberdade de iniciativa e de concorrência, sendo que, em relação a esta última, a liberdade deve ser compreendida como a que impossibilita um dos competidores dominar sozinho o mercado em que está inserido.

A definição de que a liberdade de trabalho se consubstancia em um direito fundamental decorre não só da vontade do constituinte, mas principalmente do fato de que o trabalho é meio de prover as necessidades básicas e supérfluas de cada indivíduo e, por essa razão, é instrumento de inserção social, como bem observou Fábio Rodrigues Gomes (2008, p. 65):

\footnotetext{
Sendo assim, vemos que o trabalho se torna pressuposto à idéia de autonomia, seja na sua dimensão pública, seja na sua dimensão privada. Isso porque, a partir do momento em que o indivíduo se encarrega de satisfazer suas próprias necessidades (básicas e radicais) através de sua atividade pessoal, será ele detentor não apenas de auto-respeito, mas também da capacidade de inserir-se socialmente como alguém que contribui ativamente para o desenvolvimento coletivo, na medida em que participa da divisão de tarefas inerentes aos agrupamentos humanos.
}

Assim, há uma intrínseca relação entre o direito à liberdade de trabalho e a dignidade da pessoa humana.

Na celebração do pacto de não concorrência, há, mediante determinadas condições, um inevitável cerceio ao direito de escolha de trabalho do indivíduo. 
Para que seja possível compreender se esse cerceio é razoável e legítimo, importa analisar de que maneira os direitos fundamentais devem ser protegidos, sendo imperioso distinguir a eficácia vertical da eficácia horizontal dos direitos fundamentais.

\title{
2.1 Direitos Fundamentais: Eficácia Vertical x Eficácia Horizontal
}

A eficácia vertical dos direitos fundamentais está alicerçada nos limites impostos à atuação do Estado em relação aos cidadãos, naquilo que concerne ao respeito aos direitos fundamentais.

Carlos Henrique Bezerra Leite (2011, p. 34) ensina que:

\begin{abstract}
Entende-se por eficácia vertical dos direitos fundamentais a limitação imposta pelo ordenamento jurídico à atuação dos governantes em relação aos governados, na medida em que se reconhece que entre eles há uma relação vertical de poder, ou seja, de um lado o Estado (mais forte) e de outro o indivíduo (mais fraco). A eficácia vertical, portanto, está vinculada à evolução do Estado Absoluto ao Estado Liberal, cabendo a este último o dever de respeitar e assegurar os direitos fundamentais de primeira dimensão, também chamados de direitos civis e políticos, especialmente os direitos à vida, à propriedade, à liberdade e à igualdade formal. Noutro falar, a eficácia vertical dos direitos fundamentais tem por efeito impedir interferência estatal na vida privada dos cidadãos. Por isso, a doutrina tradicional sustenta que os direitos de primeira dimensão são direitos de defesa do indivíduo frente ao Estado.
\end{abstract}

A eficácia horizontal dos direitos fundamentais, também chamada de eficácia dos direitos fundamentais entre terceiros ou de eficácia dos direitos fundamentais nas relações privadas, por seu turno, configura-se na extensão da exigência de respeito aos direitos fundamentais nas relações estabelecidas entre particulares (LEITE, 2011, p. 36).

Daniel Sarmento e Fábio Rodrigues Gomes (2011, p. 61), em artigo sobre o tema, advertem para o seguinte:

\begin{abstract}
A teoria liberal clássica limitava o alcance dos direitos fundamentais à regência das relações públicas, que tinham o Estado em um dos seus pólos. Tais direitos eram vistos como limites ao exercício do poder estatal, que, portanto, não se projetavam no cenário das relações jurídico-privadas. Hoje, tal concepção, que caracterizava o modelo de constitucionalismo liberal-burguês, revela-se anacrônica. Parece indiscutível que se a opressão e a violência contra a pessoa provêm não apenas do Estado, mas de uma multiplicidade de atores privados, presentes em esferas como o mercado, a família, a sociedade civil e a empresa, a incidência dos direitos fundamentais na esfera das relações entre particulares se torna um imperativo incontornável. Essa necessidade é ainda mais imperiosa em contextos sociais caracterizados por grave desigualdade social e assimetria de poder, como ocorre no Brasil.
\end{abstract}

Estabelecida a premissa para a exigência de respeito aos direitos fundamentais também entre os particulares, resta verificar de que maneira tal exigência deve ser realizada.

A simples inserção do particular no lugar do Estado, submetendo-o aos mesmos tipos de exigências, levaria a situações extremadas em que, por exemplo, o direito de uma pessoa 
convidar quem bem entendesse para comemorar seu aniversário poderia passar a ser questionado à luz do princípio da isonomia (SARMENTO; GOMES, 2011, p. 61).

Por essa razão, faz-se imperioso o estudo das três principais correntes doutrinárias acerca da eficácia horizontal dos direitos fundamentais: a teoria norte-americana da State Action, a teoria dos efeitos indiretos ou mediatos e a teoria da aplicabilidade direta ou eficácia imediata dos direitos fundamentais.

A State Action Doctrine é um retrato contundente do espírito liberal norte-americano.

De acordo com essa linha de pensamento, como regra geral as limitações impostas pela necessidade de respeito aos direitos fundamentais não se estendem aos particulares, sendo oponíveis apenas ao Estado.

A doutrina em tela ainda impera no judiciário estadunidense. Entretanto, sem renegála, a Suprema Corte dos Estados Unidos da América vem esboçando o que Daniel Sarmento e Fábio Rodrigues Gomes (2011, p. 64) chamam de temperamentos para a State Action Doctrine, ao adotar a chamada public function theory, segundo a qual, quando os particulares estiverem agindo em atividades que possam ser reputadas como tipicamente estatais, estarão jungidos pelas limitações impostas pelos direitos fundamentais, assim como está o Estado.

Riva Sobrado de Freitas e Alexandre Shimizu Clemente (2011, p. 167) explicam esses temperamentos da seguinte forma:

\footnotetext{
O artifício encontrado pelos pensadores norte-americanos consistia em imputar ao Estado a responsabilidade por atos privados ou em equipará-los a atos estatais. Dessa forma, não aceitando expressamente a vinculação dos particulares, pode-se chegar a um resultado equiparável às teorias que aceitam a produção de efeitos em face da incidência dos Direitos Fundamentais.
}

Exemplifica a modulação da teoria da State Action Doctrine o caso Marsh vs Alabama $^{15}$, em que se discutia se uma empresa privada, que possuía um terreno em que existiam ruas, casas e estabelecimentos comerciais, à semelhança de uma pequena cidade, poderia ou não proibir que testemunhas de Jeová pregassem dentro de sua propriedade.

A Suprema Corte Estadunidense decidiu por ser inválido esse tipo de proibição, eis que, ao manter uma cidade privada, a empresa se equipararia ao Estado, razão pela qual deveria se sujeitar à $1^{\mathrm{a}}$ Emenda da Constituição Norte-Americana, que garante a liberdade de culto.

\footnotetext{
${ }^{15}$ ESTADOS UNIDOS DA AMÉRICA. Suprema Corte. Caso Marsh v. Alabama, no 114. Decisão proferida em 1946, reprodução do julgamento disponível em: https://www.law.cornell.edu/supremecourt/text/326/501, consultado no dia 22.02.2015.
} 
Em outro sentido, foi desenvolvida por Günter Dürig a chamada Mittelbare Drittwirkung, ou teoria dos efeitos indiretos ou imediatos, que se estabeleceu como a concepção dominante no direito germânico.

Nas palavras de Daniel Sarmento e Fábio Rodrigues Gomes (2011, p. 66), "trata-se de construção intermediária entre a que simplesmente nega a vinculação dos particulares aos direitos fundamentais, e aquela que sustenta a incidência direta destes direitos na esfera privada".

A proposta elaborada por Dürig parte da premissa de que seriam necessárias "pontes" ligando o direito privado aos valores constitucionais consubstanciados nos direitos fundamentais.

Essas pontes são representadas pelas cláusulas gerais e conceitos jurídicos indeterminados, utilizados pelo legislador infraconstitucional como "portas de entrada" para os valores constitucionais, centrados no princípio da dignidade da pessoa humana (SARMENTO; GOMES, 2011, p. 67).

Diversas são as críticas lançadas em face dessa teoria.

Por um lado, há quem entenda que a impregnação do Direito Privado com valores constitucionais aviltaria o princípio da legalidade, aumentando a insegurança nas searas civil, comercial e trabalhista. ${ }^{16}$

Por outro, a doutrina de Dürig também é objeto de crítica por parte daqueles que entendem que ela não garante uma tutela integral dos direitos fundamentais, eis que é dependente do legislador ordinário. ${ }^{17}$

Por fim, ainda existem os detratores que assinalam para o fato de que a doutrina em análise nada mais faz do que remeter para um procedimento de interpretação conforme a constituição, que já é sedimentado. ${ }^{18}$

Interessa observar que, na doutrina nacional, a teoria da eficácia mediata não encontra muitos adeptos, haja vista a ampla maioria dos autores se filiar à teoria da eficácia imediata dos direitos fundamentais, a seguir analisada.

Também de origem germânica, a teoria da eficácia imediata foi desenvolvida por Hans Carl Nipperdey, que atuou como juiz no Tribunal Federal do Trabalho, na década de 50 do século passado ${ }^{19}$.

\footnotetext{
${ }^{16}$ Por todos, A. Kol, cf. SARMENTO, Daniel; GOMES, Fábio Rodrigues. Op. Cit., p 70.

${ }_{17}$ Neste sentido, Pedro Veja Garcia, cf. SARMENTO, Daniel; GOMES, Fábio Rodrigues. Op. Cit., p 70.

${ }_{18}$ Assim se posiciona Juan Maria Biolbao Ubillas, cf. SARMENTO, Daniel; GOMES, Fábio Rodrigues. Op. Cit., p 70.

19 RÜCKERT, Joachim. "Nipperdey, Hans Carl" em: Nova biografia Germânica, p. 280 a 282 [versão online]. Disponível em: http://www.deutsche-biographie.de/ppn118735519.html, consultado no dia 25.02.2015.
} 
O Estado estritamente liberal é marcado pela dicotomia entre o Direito Público e o Direito Privado, isto porque enquanto o primeiro tem por finalidade a ordem e a segurança geral, sendo somente possível fazer aquilo que está autorizado pela norma; o segundo rege-se pela igualdade e pela liberdade, sendo permitido tudo aquilo que não é proibido pelo ordenamento jurídico.

Nos dias atuais, essa dicotomia já não é absoluta e intransponível, pois cada vez mais se defende a interseção do Direito Constitucional nas relações privadas.

Nesse sentido, destaca-se a teoria de Nipperdey, o qual defende em sua tese que os direitos fundamentais são permeados por um caráter dúplice, sendo alguns invocáveis apenas em face do Estado e outros vinculando também os particulares, sem a dependência de qualquer mediação legislativa (SARMENTO; GOMES, 2011, p. 71).

Desta forma, a teoria da eficácia direta ou imediata propõe que alguns direitos fundamentais podem ser aplicados diretamente às relações privadas, ou seja, entre particulares, e não somente entre estes e o Estado.

Nipperdey justifica suas afirmações com o fundamento de que as ameaças aos direitos fundamentais na sociedade moderna nem sempre vêm do Estado (SARMENTO; GOMES, 2011, p. 71). Assim, há atividades privadas que possuem um caráter público, na quais não podem deixar de haver aplicação de direitos e garantias fundamentais, ainda mais diante da ausência de igualdade econômica entre os particulares.

Nesse sentido, Ana Paula de Barcellos frisa que:

\begin{abstract}
A garantia dos direitos individuais clássicos tornou-se insuficiente, na medida em que o Estado deixou de ser o único opressor. A lógica aleatória e impessoal do mercado capitalista livre era capaz de negar aos indivíduos bens absolutamente fundamentais, a despeito da liberdade garantida e do empenho que se pudesse empregar para obter tais bens. Sem essas condições materiais mínimas, e.g., de educação, saúde, alimentação, informação etc., os direitos individuais e políticos eram pouco mais que papel e tinta. (BARCELLOS, 2008, p. 131-132)
\end{abstract}

Um ordenamento jurídico em que a ordem econômica é fundada na valorização do trabalho humano e na livre iniciativa e que tem por fim assegurar a todos existência digna, conforme os ditames da justiça social ${ }^{20}$, como é o caso do Brasil, não pode conceber o direito privado como um sistema independente, desconjuntado das premissas majoritárias do Estado Social e da constitucionalização dos direitos sociais.

Apreende-se que a adoção da teoria da aplicabilidade direta pelo legislador brasileiro está em harmonia com o fundamento da República Federativa do Brasil, que visa promover de

\footnotetext{
${ }^{20}$ Esta previsão está contida no artigo 170 da Constituição da República de 1988.
} 
modo equilibrado os valores sociais do trabalho e da livre iniciativa, como consta no artigo $1^{\circ}$, inciso IV, da Constituição Federal ${ }^{21}$.

Aliás, a Constituição de 1988 ainda dispõe, em seu artigo $3^{\circ}$, inciso III, que a República Federativa do Brasil tem como fundamento a busca da redução das desigualdades sociais e da construção de uma sociedade justa e solidária. Com isso, o constituinte visa, ao promover a liberdade, a justiça e a emancipação social dos cidadãos, garantir um Estado Social ao Estado brasileiro.

Ademais, o artigo $5^{\circ}$, parágrafo $1^{\circ}$, da Constituição Federal, determina que "as normas definidoras dos direitos e garantias fundamentais têm aplicação imediata”. Isto significa que o constituinte, abarcando todos esses direitos, decidiu dar eficácia plena e aplicação imediata para o seu exercício.

Logo, a omissão legislativa não pode ser empecilho ao seu exercício, cabendo ao cidadão que se sentir lesado utilizar das ações constitucionais para garantir a efetividade de tais regras, que se tornam basilares no ordenamento jurídico brasileiro.

Oportuna é a lição de Ingo Wolfgang Sarlet, que sobre o tema explica:

\begin{abstract}
Se, portanto, todas as normas constitucionais sempre são dotadas de um mínimo de eficácia, no caso dos direitos fundamentais, à luz do significado outorgado ao art. $5^{\circ}, \S 1^{\circ}$, de nossa Lei Fundamental, pode afirmar-se que aos poderes públicos incumbem a tarefa e o dever de extrair das normas que os consagram (os direitos fundamentais) a maior eficácia possível, outorgando-lhes, neste sentido, efeitos reforçados relativamente às demais normas constitucionais, já que não há como desconsiderar a circunstância de que a presunção da aplicabilidade imediata e plena eficácia que milita em favor dos direitos fundamentais constitui, em verdade, um dos esteios de sua fundamentalidade formal no âmbito da Constituição. (SARLET, 2007, p. 285)
\end{abstract}

Nas palavras de Riva Sobrado de Freitas e Alexandre Shimizu Clemente (2011, p. 172), a teoria de Nipperdey e a de Dürig se diferenciam na seguinte medida:

\begin{abstract}
A grande diferença, portanto, dessa teoria para a Tese dos Efeitos Indiretos é a possibilidade dos Direitos Fundamentais produzirem seus feitos sem a necessidade de pontes ou portas de entrada oriundas do Direito Privado, pois para NIPPERDEY, aqueles se constituem verdadeiros direitos subjetivos dos particulares em suas relações. Sendo assim, isso leva à imperiosa conclusão que em termos concretos, podem os indivíduos recorrerem aos direitos fundamentais para fazê-los valer contra particulares.
\end{abstract}

Assim como ocorreu com a tese de eficácia indireta, a teoria de Nipperdey foi igualmente criticada.

Nos dizeres de Claus-Wilheim Canaris (2006, p. 227):

\footnotetext{
${ }^{21}$ “Art. $1^{\circ}$ A República Federativa do Brasil, formada pela união indissolúvel dos Estados e Municípios e do Distrito Federal, constitui-se em Estado Democrático de Direito e tem como fundamentos:

[...] IV - os valores sociais do trabalho e da livre iniciativa;” BRASIL. Constituição da república Federativa do Brasil (de 5 de outubro de 1988). Disponível em: < http://www.planalto.gov.br/ccivil_03/constituicao/constituicaocompilado.htm>. Acesso em: 5 jul 2015.
} 


\begin{abstract}
Ela [a relação entre os direitos fundamentais e o Direito Privado] radica no fato de os direitos fundamentais, enquanto parte da Constituição, terem um grau mais elevado na hierarquia das normas do que o Direito Privado, podendo, por conseguinte, influenciá-lo. Por outro lado, a Constituição, em princípio, não é o lugar correto nem habitual para regulamentar as relações entre cidadãos individuais e entre pessoas jurídicas. Nisso consiste, muito pelo contrário, a tarefa específica do Direito Privado, que desenvolveu nesse empenho uma pronunciada autonomia com relação à Constituição; e isso não vale apenas em perspectiva histórica, mas também no tocante ao conteúdo, pois o Direito Privado, em regra, disponibiliza soluções muito mais diferenciadas para conflitos entre os seus sujeitos do que a Constituição poderia fazer.
\end{abstract}

Não obstante os argumentos em sentido contrário, a teoria se solidificou em meio aos doutrinadores pátrios, a exemplo de Daniel Sarmento e Fábio Rodrigues Gomes (2001, p. 71), que defendem Nipperdey da seguinte forma:

\begin{abstract}
Os adeptos da teoria da eficácia imediata dos direitos fundamentais nas relações privadas não negam a existência e especificidades nesta incidência, nem a necessidade de ponderar o direito fundamental em jogo com a autonomia privada dos particulares envolvidos no caso. Não se trata, portanto, de uma doutrina radical, que possa conduzir a resultados liberticidas, ao contrário do que sustentam seus opositores, pois ela não prega a desconsideração da liberdade individual no tráfico jurídico-privado, mas antes impõe que seja devidamente sopesada na análise de cada situação concreta.
\end{abstract}

E a propósito do presente estudo, sobreleva destacar a necessidade de ponderação de um direito fundamental - liberdade de trabalho - com outros direitos constitucionalmente garantidos (livre iniciativa e concorrência), de forma a alcançar uma solução para o conflito.

Para Renato Rua de Almeida (2010, p. 144), ainda que os direitos fundamentais dos trabalhadores tenham uma prevalência prima facie sobre os demais direitos constitucionais, será o método da ponderação de forma casuística que resolverá o conflito entre princípios normativos, valendo-se do princípio da proporcionalidade e de seus subprincípios da necessidade, adequação e da razoabilidade, de maneira a resolver a questão.

Isso porque a preponderância dos direitos fundamentais do trabalhador não significa e tampouco pode significar a inviabilização da atividade econômica, sob pena da própria derrocada do direito fundamental ao trabalho, uma vez que a inviabilização da atividade econômica teria justamente essa consequência.

No mesmo sentido, Virgílio Afonso da Silva (2010, p. 255) explica que "toda norma que garante um direito fundamental tem alguma limitação em sua eficácia. Ou seja: todas as normas são de eficácia limitada”.

Seguindo o mesmo raciocínio, Alexandre de Moraes (1999, p. 58) informa que "os direitos e garantias fundamentais consagrados pela Constituição Federal [...] não são ilimitados, uma vez que encontram limites nos demais direitos igualmente consagrados pela Carta Magna (Princípio da Relatividade ou convivência das liberdades públicas)”. 
Assim, adotando o ensinamento de Renato Rua de Almeida, sobre a necessidade de aplicação dos subprincípios que instruem o princípio da proporcionalidade, pode-se esclarecer que: i) de acordo com o subprincípio da adequação, a medida restritiva tem que ser apta ou adequada para a proteção do direito almejada; ii) o subprincípio da necessidade busca impor a indagação acerca de ser a medida intentada realmente necessária à efetividade do direito que se pretende proteger e iii) e o subprincípio da razoabilidade consiste em ponderar o peso da restrição imposta e o resultado buscado(2012, p. 65-66).

\subsection{A Proporcionalidade na Celebração do Pacto de Não Concorrência}

No caso da celebração do pacto de não concorrência, verifica-se que ele atende a todos os parâmetros acima expostos.

Sendo o objetivo do pacto o de preservar informações sigilosas e segredos de negócio do empregador, de forma a brecar sua utilização em ato concorrencial, a medida se afigura adequada, uma vez que o impedimento imposto ao trabalhador faz com que seja alcançado o fim proposto.

Por outro lado, a adoção da medida se afigura necessária, eis que nenhuma outra seria tão eficaz para garantir o impedimento do trabalhador em implementar concorrência a seu antigo empregador.

Por fim, a celebração do pacto de não concorrência, observados certos requisitos de validade, em especial o estabelecimento de uma recompensa financeira pela interdição, acompanhada de uma limitação temporal para o impedimento, demonstra que a restrição imposta é razoável para preservar a livre iniciativa e concorrência.

Não por outra razão, Estevão Mallet (2005, p. 123-124) defende que a celebração do pacto de não concorrência não ofende o direito fundamental de liberdade de trabalho, afirmando que:

\footnotetext{
Em primeiro lugar, nenhum direito reveste-se de caráter absoluto. 'Al concetto di diritto - adverte Ferrara - non è incompatibile quello di limite, anzi vi è inerente'. Não se passa de modo diverso com o direito de exercício de trabalho, tutelado pelo art. $5^{\circ}$ inciso XIII, da Constituição, que tampouco é absoluto, consoante reiteradamente enfatizado pela jurisprudência. E tanto é assim que as alíneas "c" e "g", do art. 482, da CLT, embora limitem, de alguma forma, a possibilidade de trabalho pelo empregado, nunca foram consideradas inconstitucionais. Ademais, mesmo em face de texto mais amplo, como o do art. 72, §24, da Constituição de 1891, em que se garantia 'o livre exercício de qualquer profissão moral, intelectual e industrial', a doutrina não exitou em identificar a existência de limites implícitos, relacionados com a proteção de valores socialmente relevantes.
} 
No mesmo sentido, colhe-se o entendimento de Alice Monteiro de Barros (2009, p. 259), Oris de Oliveira (2005, p. 164-165) e Adriana Carreira Calvo (2005, s.p.).

Conclui-se, portanto, que a celebração do pacto de não concorrência não atenta contra a garantia fundamental de direito ao trabalho, afigurando-se como um expediente legítimo para a salvaguarda dos interesses empresariais, que tem por escopo fomentar a livre iniciativa e concorrência.

\section{CONCLUSÃO}

As sociedades empresariais investem cada mais vez em desenvolvimento de novas técnicas e recursos tecnológicos, objetivando a manutenção e crescimento de sua participação nos mercados em que estão inseridas.

A par disso, estratégias de negócio montadas com base em informações sensíveis e preciosas vão alavancando o desenvolvimento de suas atividades econômicas.

Ao longo do processo produtivo e econômico, o conhecimento de técnicas, métodos, fórmulas, listas de clientes e fornecedores etc. vão sendo conferidos aos empregados, que dependem de tais informações para o exercício de suas atividades laborativas.

Tais empregados passam a ter um valor para os concorrentes de seus empregadores, que não se relaciona apenas à sua formação e preparo técnico, advindo, também, das informações sigilosas e segredos de negócio que tiveram conhecimento em razão do vínculo de emprego mantido.

Considerando-se esse estado de coisas, o presente artigo se propôs a estudar a viabilidade, pela ótica constitucional, de se impedir que os empregados que tenham acesso a segredos de negócio e informações sigilosas incorram em atos de concorrência aos seus antigos empregadores, mediante a celebração do pacto de não concorrência após o término do contrato de emprego.

Para tanto, foi necessário apurar se a celebração do pacto de não concorrência ofendia a liberdade de trabalho, erigida ao status de direito fundamental pela Constituição de 1988, de maneira a verificar sua compatibilidade com o ordenamento constitucional vigente.

De fato, o argumento mais repetido pelos que se opõem à cláusula de não concorrência após a rescisão do contrato de emprego é justamente o de que ele ofende o direito garantido no artigo $5^{\circ}$, inciso XIII, da Constituição Federal.

Em razão disso, foi feito um balanço entre a liberdade de trabalho em contraponto à livre iniciativa, à livre concorrência e ao direito de propriedade. 
Consultando todos os textos constitucionais que vigoraram no Brasil, pôde-se verificar que, a despeito de os direitos fundamentais contarem com eficácia horizontal, eles não são absolutos e encontram limite nos demais preceitos constitucionais.

A necessidade de preservação de um ambiente concorrencial sadio e o interesse social envolvido na manutenção da ordem econômica levam a uma ponderação de interesses que permite constatar que o direito individual de liberdade de trabalho não se sobrepõe à necessidade coletiva de prestigiar uma ordem que propugne a livre iniciativa e a livre concorrência, o que conduz à conclusão de que a celebração do pacto de não concorrência após o término da relação de emprego não atenta contra o ordenamento constitucional vigente.

\section{REFERÊNCIAS BIBLIOGRÁFICAS}

ALMEIDA, Renato Rua de. Direitos Fundamentais Aplicados ao Direito do Trabalho, v. II. São Paulo: LTr. 2012.

BARCELLOS, Ana Paula de. A eficácia jurídica dos princípios constitucionais: o princípio da dignidade da pessoa humana. Rio de Janeiro: Renovar, 2008.

BARROS, Alice Monteiro de. Curso de direito do trabalho. 5. ed. rev. e ampl. São Paulo: LTr, 2009.

BRASIL. Constituição Política do Império do Brazil (de 25 de março de 1824).

Disponível em:

<http://www.planalto.gov.br/ccivil_03/Constituicao/Constitui\%C3\%A7ao24.htm>. Acesso em: 24 mar 2013.

Constituição da República dos Estados Unidos do Brasil (de 24 de fevereiro de 1891). Disponível em: < http://www.planalto.gov.br/ccivil_03/constituicao/constituicao91.htm>. Acesso em: 5 jul 2015

Constituição da República dos Estados Unidos do Brasil (de 16 de julho de 1934). Diário Oficial da União. Disponível em: < http://www.planalto.gov.br/ccivil_03/constituicao/constituicao34.htm>. Acesso em: 5 jul 2015

Constituição da República dos Estados Unidos do Brasil (de 10 de novembro de 1937). Diário Oficial da União. Disponível em: < http://www.planalto.gov.br/ccivil_03/constituicao/constituicao37.htm>. Acesso em: 5 jul 2015 
Constituição da República dos Estados Unidos do Brasil (de 18 de setembro de 1946). Diário Oficial da União. Disponível em: < http://www.planalto.gov.br/ccivil_03/constituicao/constituicao46.htm>. Acesso em: 5 jul 2015

Constituição da República Federativa do Brasil de 1988. Diário Oficial da União. Disponível em: < http://www.planalto.gov.br/ccivil_03/constituicao/constituicao.htm>. Acesso em: 20 jan 2014

CALMON, Pedro. Curso de Direito Constitucional Brasileiro. Rio de Janeiro: Freitas Bastos, 1937.

CALVO, Adriana Carrera. Os aspectos legais e a validade da cláusula de nãoconcorrência no Brasil. Revista Jus Navigandi, Teresina, ano 10, n. 616, 16 mar. 2005. Disponível em: <http://jus.com.br/artigos/6450>. Acesso em: 11 jul. 2015.

CANARIS, Claus-Wilheim. A influência dos direitos fundamentais sobre o direito privado na Alemanha. In: Sarlet, Ingo Wolfgang (org.). Constituição, Direitos Fundamentais e Direito Privado. 2 ed. Porto Alegre: Livraria do Advogado, 2006.

ESTADOS UNIDOS DA AMÉRICA. Suprema Corte. Caso Marsh v. Alabama, no 114. Decisão proferida em 1946, reprodução do julgamento disponível em: https://www.law.cornell.edu/supremecourt/text/326/501, consultado no dia 22.02.2015

FREITAS, Riva Sobrado de; CLEMENTE, Alexandre Shimizu. Direitos Fundamentais e Justiça. Revista do Programa de Pós-Graduação, Mestrado e D. Porto Alegre, v.5, n.15, p.159-185, jun. 2011.

GOMES, Fábio Rodrigues. O Direito Fundamental ao Trabalho. Rio de Janeiro: Lumen Juris Editora, 2008

LEITE, Carlos Henrique Bezerra. Eficácia Horizontal dos Direitos Fundamentais na Relação de Emprego. Revista Brasileira de Direito Constitucional - RBDC, São Paulo, n. 17, 2011.

MALLET, Estevão. Cláusula de não concorrência em contrato individual de trabalho. Revista da Faculdade de Direito da Universidade de São Paulo, v. 100, p. 121-146, jan./dez. 2005. Disponível em: Disponível em: <

http://www.revistas.usp.brrfdusparticleviewFile6766770275>. Acesso em: 28 jun 2015

MORAES, Alexandre de. Direito Constitucional. São Paulo: Atlas S/A, 1999.

MORAES FILHO, Evaristo de. Introdução do Direito do Trabalho. 4. ed. São Paulo: Ltr, 1986.

NETO, Célio Pereira Oliveira. Liberdade de Trabalho e a cláusula de não concorrência. 2012. Disponível em:

<http://www.celioneto.adv.br/news/08.2012/liberdade_de_trabalho_e_a_clausula_de_nao_co ncorrencia.pdf $>$. Acesso em: 6 jul 2015 
OLIVEIRA, Oris de. Exclusão de Concorrência no Contrato de Emprego. São Paulo: LTr, 2005.

RÜCKERT, Joachim. "Nipperdey, Hans Carl" em: Nova biografia Germânica, p. 280 a 282 [versão online]. Disponível em: http://www.deutsche-biographie.de/ppn118735519.html, consultado no dia 25.02.2015.

SARLET, Ingo Wolfgang. A Eficácia dos Direitos Fundamentais. $7^{\text {a }}$ ed. Porto Alegre: Livraria do Advogado, 2007.

SARMENTO, Daniel; GOMES, Fábio Rodrigues. A eficácia dos direitos fundamentais nas relações entre particulares: o caso das relações de trabalho. Revista do Tribunal Superior do Trabalho, São Paulo, v. 77, n. 4, 2011.

SILVA, José Afonso da, Curso de Direito Constitucional Positivo. 13. ed. São Paulo: Melhoramentos, 1997.

SILVA, Virgílio Afonso da. Direitos fundamentais - conteúdo essencial, restrições e eficácia. São Paulo: Malheiros, 2010.

SÜSSEKIND, Arnaldo; MARANHÃO, Délio e VIANNA, Segadas. Instituições de Direito do Trabalho, vol. I. Rio de Janeiro: Livraria Freitas Bastos, 1957. 